\section{FATORES DETERMINANTES NA EVASÃO ESCOLAR, NAS SÉRIES FINAIS (6. ANO A e E) DO ENSINO FUNDAMENTAL DA ESCOLA MUNICIPAL JARBAS GONÇALVES PASSARINHO DE ITUPIRANGA - PA}

DETERMINANT FACTORS IN SCHOOL EVASION, IN THE FINAL SERIES (6th YEAR A AND E) OF THE FUNDAMENTAL EDUCATION OF THE MUNICIPAL SCHOOL JARBAS GONÇALVES PASSARINHO OF THE CITY OF ITUPIRANGA

Antonio Batista dos Santos ${ }^{1}$

RESUMO: É compreensível que muitos dos problemas surgidos no processo de ensino e aprendizagem, são por falta de uma série de fatores, como o compromisso da própria escola, da família e as condições educativas ofertadas pelo poder público. Pois seriam eles que deveriam exercer seus papeis na sociedade que estão inseridos. Mas, além dos fatores já mencionados, existe uma série de fatores que contribuem incisivamente para o agravamento desses problemas. Aqui pode-se enumerar os mais peculiares: as condições sociais dos pais ou responsáveis por estes alunos, o uso excessivo do álcool na adolescência, a gravidez na adolescência, o trabalho infantil, os fatores climáticos, as dificuldades de acesso às escolas, a falta de atração por parte da escola, a falta de interesse, etc. Como se ver, o estudo aqui exposto tem com finalidade, realizar uma análise minuciosa e, explicar os possíveis motivos que levam bastante os nossos alunos do 6.. ano $\mathrm{A}$ e $\mathrm{C}$, nos turnos matutino e vespertino respectivamente, a evadirem da escola e não concluírem na maioria das vezes, nem o ensino fundamental. O trabalho recorreu a entrevistas através de questionários, incluindo 4 (quatro) alunos e as suas respectivas mães e uma professora de português.

Palavras-chave: Adolescência. Fatores da evasão escolar. Series finais do ensino fundamental.

ABSTRACT: It is understandable that many of the problems that arose in the teaching and learning process, are due to the lack of a series of factors, such as the commitment of the school itself, the family and the educational conditions offered by the government. For they would be the ones who should exercise their roles within the society they are inserted in. But, in addition to the factors already mentioned, there are a number of factors that strongly contribute to the worsening of these problems. Here we can list the most peculiar: the social

\footnotetext{
${ }^{1}$ Licenciado Pleno em Geografia - UEMA (2004), Biologia - UFPA (2015) e, Pedagogia - FATEH (2017). Pós em Ensino de Geografia - FATEH (2007) Educação Social- UEPA para a Juventude Pro jovem-Urbano UEPA (2012). E-mail: antonioyazber@gmail.com.
} 
conditions of the parents or guardians of these students, the excessive use of alcohol in adolescence, pregnancy in adolescence, child labor, climatic factors, difficulties in accessing schools, the lack of of attraction on the part of the school, the lack of interest, etc. As can be seen, the study exposed here aims to carry out a thorough analysis and explain the possible reasons that lead our 6th grade students $\mathrm{A}$ and $\mathrm{C}$, in the morning and afternoon shifts, respectively, to drop out of school and not finish at school. most of the time, not even elementary school. The work made use of interviews through questionnaires, including 4 (four) students and their respective mothers and a Portuguese teacher.

Keywords: Adolescence. School dropout factors. Final series of elementary school.

\section{INTRODUÇÃO}

A educação pública brasileira, na modalidade Educação Básica", que deveria possibilitar aos jovens, condições de aprendizagem e preparação para o mercado de trabalho, está em um estágio desproporcional aos interesses dos jovens e da oferta de conhecimento para atender a exigem do mercado tecnológico e globalizado.

No contexto educacional em que perpassa o processo de ensino e aprendizagem nas escolas, os alunos são excluídos pela própria ideologia da educação, pois à medida que a educação insiste em viver e aplicar práticas e métodos tradicionais, os alunos enxergam e busca caminhar com a evolução técnico-científico e globalizado.

Partindo dessa divergência de visão e tempo, associados aos fatores extra escolares surgem a educação que ao invés de incluído, exclui inocentemente, os alunos do processo de ensino técnico, tecnológico, científico, global, moderno e, aprisiona no passado tradicional e fechado ao mundo do saber. Com isso aparecem os fatores determinantes para o elevado índice de alunos que deixam a escola para viverem os espaços que culminam com os seus interesses e atração, ocasionando assim a chamada evasão escolar em massa.

Diante das prorrogativas mencionadas sobre a oferta e a qualidade da educação básica, fez-se um estudo de campo na escola Jarbas Gonçalves Passarinho com exame do Projeto Político Pedagógico - PPP e demais arquivos da secretaria da escola em aludo com dados que permitisse analisar as duas turmas do 60 ano do ensino fundamental - Turmas: A e E, matutino e vespertino respectivamente, dos anos: 2017 e 2018, para fazer um comparativo sobre um fator muito argumentado sobre o déficit de aprendizagem nas regiões próximas à linha do Equador, que é a temperatura, além de outros.

É compreensível que os fenômenos naturais, são incisivamente, obstáculos determinantes para contribuir com a evasão escolar dos alunos da região amazônica, pois aqui existe elevadas temperaturas, ocasionando um período de chuva intensa, aonde a sua 
frequência destrói as estradas que, por sua vez, são ramais em barro cru, ficando assim intrafegáveis. E como cerca de $40 \%$ dos alunos que estudam na zona urbana, vivem em áreas rurais, com as suas ausências engrossam as estatísticas do número de alunos evadidos durante cada ano letivo.

As estatísticas da evasão na escola apontam para números preocupantes, o que justificou a pesquisa nesse assunto aqui citado. Usa-se o apontamento da mesma e as possíveis estratégias para garantir a diminuição e até mesmo combater com urgência esse dado negativo no município de Itupiranga-PA, e principalmente, na escola Jarbas Gonçalves Passarinho.

Observa-se ainda, que além dos fatores mencionados, têm-se os fatores sociais, como o alto índice de filhos de mães solteiras, analfabetas, sem funções remunerativas, que na maioria das vezes sobrevivem com os benefícios do governo Federal, principalmente nas últimas décadas. Como se ver, muitos desses alunos tomam caminhos diferentes para poder ajudar na renda doméstica ou para saciar o desejo de infância (roubo, furto, crime, prostituição, etc.), nesse processo, aumenta se a migração que, no que lhe concerne, reflete em problemas diversos. Todas essas práticas, levam os alunos a abandonarem a escola e, mais uma vez contribui para o crescimento da evasão escolar.

Sabe-se ainda que a disfunção ou até mesmo a estruturação e a modernização dos espaços físicos dos ambientes escolares, assim como a falta de formação continuada dos docentes e ainda a falta de inserção das tecnologias da educação nas aulas diariamente, limitam e bloqueiam o avanço e consequentemente o desenvolvimento da aprendizagem dos alunos. Somando tudo isso e mais a ausência da família na escola, culmina com uma evasão escolar exagerada.

É consenso também, que a falta da inserção da tecnologia na educação não se limita apenas e dinamizar e possibilitar os debates educacionais. A sua ausência, formaliza uma condição imprópria ao ensino e a aprendizagem. Pois, além de dificultar em quase tudo, ainda deixa o professor sem o conhecimento vigente, aquele que interessa ao jovem da atualidade. Nesses termos, é essencial que o profissional tenha cuidados redobrado no manuseio das suas atividades e na aplicabilidade das mesmas para a compreensão do estudante.

Para cientificar e explicitar a pesquisa, analisa e implementa o pensamento de estudiosos dos parâmetros educacionais. A mudança de estratégias e relacionamento com os outros seres e ambiente, contribui com novas descobertas. Segundo Wallon, o homem é um ser essencialmente social impossível, portanto, de ter pensado fora do contexto da sociedade em que nasce e vive. Em outras palavras, o homem não social, o homem considerado molécula 
isolada do resto dos seus semelhantes, o homem visto como independente das influências dos diversos grupos que frequenta, o homem visto como imune aos ligados da história e da tradição, este homem, simplesmente não existe (WALLON, 1992).

A sociedade precisa se reinventar para os novos tempos, para inteirar-se, do saber. Pois, escola é o local de inteira inclusão e de novos saberes, por isso deve transformar o educando num ser social pensante existente. Nesse contexto, compreende-se a educação como único caminho para transformação humana social dos indivíduos, conduzindo-os para uma visão crítica, conscientizando e preparando-os para viverem em sociedade e assumindo a sua cidadania (MARX, 1991).

Segundo Silva, Pimentel e Finardi (2014, p. 245), a evasão ocorre com a separação gradual entre estudantes e instituição escolar e está relacionada a fatores como a demográficos, econômicos, relacionados à família e a fatores individuais, todos esses não excludentes, que influenciam na decisão de deixar a escola.

De acordo com Queiroz (200I), de maneira geral, os estudos que analisam o fracasso escolar, o fazem a partir de duas abordagens diferentes: a primeira, que explicará por fatores externos à escola, e a segunda, a partir de fatores internos. Dentre os fatores externos são apontados a necessidade de o (a) aluno (a) trabalhar, condições de aprendizagem da criança, as condições da família, e as desigualdades sociais. E dentre os fatores internos, são apontados a própria escola e, a linguagem do professor.

Dessa forma a criança ou o jovem, podem ser culpabilizados pelo seu próprio fracasso por motivo como a pobreza, a desigualdade social, a necessidade de trabalhar, a falta de esforço ou de interesse, (Queiroz).

\section{DESENVOLVIMENTO}

A pesquisa em análise para conhecimento e levantamento de dados sobre a hipótese do elevado grau da evasão escolar no Município de Itupiranga, foi realizada na escola mais centralizada da sede do município, ou seja, no centro da cidade, com a finalidade de averiguar os elementos primordiais de tais variantes que expressam esses dados da evasão escolar. Escola Municipal de Ensino Fundamental Jarbas Gonçalves Passarinho, localizada a Av. I4 de julho, $\mathrm{s} / \mathrm{n}$ centro de Itupiranga-PA.

Segundo relatório censitário demonstrativo da SEMED, a evasão escolar deste município do Sudeste paraense, é assustador e, a escola acima citada, amarga o topo desses dados com o mais alto índice de evasão escolar há mais de uma década. Após esse notório 
resultado negativo nos dados mais recentes, muitos questionamentos foram feitos, com o mesmo objetivo desta pesquisa em curso.

O estudo em questão promovido por uma pesquisa de campo, com a aplicação de questionário de perguntas e respostas a alunos e pais de alunos matriculados nas mesmas séries comparadas por dados foi realizada entre os meses de setembro de 2019 e março de 2020 . Onde os entrevistados responderam uma série de perguntas:

I) A merenda escolar interfere na aprendizagem dos estudantes?

Para os pais a resposta é sim. Pois, a maioria dos jovens vem sem ter tomado nem o café simples se quer; com isso tira a atenção e compromete a aprendizagem. Já para alunos a merenda não atrapalha e sim a falta de atenção da maioria;

2) As condições socioeconómicas atrapalham o desenvolvimento dos alunos?

Nessa questão houve uma divisão de opinião por parte dos pais, alguns entendem que sim. Para os outros, as condições econômicas e sociais não interferem na aprendizagem, para estes, a aprendizagem depende mais do interesse. Para os alunos, esses fatores atrapalham os seus desenvolvimentos, principalmente pelos constrangimentos diante daqueles que têm poder;

3) Para os filhos de mães separadas, têm dificuldade de aprendizagens?

Esse fator foi visto como um entrave essencial para o abano escolar, pois os filhos quando decidem não estudar mais, as mães não têm poder sobre os mesmos para continuar na escola;

4) Sobre a distância da escola para os bairros mais distantes, atrapalha o desenvolvimento escolar?

Para a maioria absoluta dos pais e dos alunos pesquisados, principalmente aqueles que moram em bairros longes ou na zona rural, afirmam que esse fator dificulta demais a presença dos alunos e, as vezes levam a desistir facilmente, principalmente no período chuvoso;

5) A qualidade da saúde no município contribui também para o baixo rendimento e provável evasão escolar dos alunos?

Todos concordaram que sim. Pois, moramos numa cidade sem saneamento básico e com baixa coleta de lixo etc.;

6) Questionou também a temperatura como fator relevante à evasão escolar no município. $O$ clima da região atrapalha a aprendizagem?

Nessa pergunta houve opiniões opostas, mas, mesmo assim ficou comprovado que sim, pois se trata de uma região com elevadas temperaturas e escola sem equipamentos para resfriamento;

7) A formação dos professores está à altura para uma boa qualidade de aprendizagem. 
Por unanimidade, os professores têm excelentes formações especificas;

8) A qualidade e inovação das aulas atraem ao ideal os estudantes?

Nessa pergunta só uma mãe disse acreditar que sim. Já os alunos ficaram divididos;

9) Às condições físicas da escola são adequadas para uma boa aprendizagem?

Para a maioria dos pais e estudantes, essas condições são insuficientes e velhas. Por tanto, faz com que os alunos não se sintam à vontade para aprender;

Io) Sobre a equipe gestora da escola. Ela atua adequadamente nas suas funções? Para alunos e os pais, essa equipe não deixa claro o papel de cada um, o que mais se relaciona com a função é o diretor.

Diante do exposto percebe se que a essencialidade do funcionamento da escola para adquirir de fato a aprendizagem, precisa se vencer muitas outras barreiras como diz Arroyo.

As desigualdades sociais presentes na sociedade brasileira, segundo Arroyo, (2016), são consequências das diferenças de classes e marcam o abandono escolar nas camadas mais baixas: não são as diferenças regionais e climáticas que marcam o sucesso ou o fracasso escolar, mais sim, a desigualdade social, já que é a escola das classes trabalhadoras que vêm a fracassar em todos os lugares.

Após análise de várias teses de estudiosos, percebe se que a questão da evasão escolar, está mais além da nossa simples compreensão e, inclui variantes que ora é vista com falta, já em outras situações pode ser vista com excesso, isso quando se analisa as regiões economicamente.

Lüscher, (20II), enfatiza que além da diversidade de situações que podem ser vistas como evasão escolar, existe também o problema de entender as suas causas. Trata - se de algo difícil de resolver porque, de forma análoga, os outros processos vinculados ao desempenho escolar, a evasão escolar é influenciada por conjunto de fatores relacionados tanto ao estudante e à família quanto à escola e comunidade que vive.

Para Neri (2009, p.5I) as regiões com maior oportunidade de trabalho, são as que mais atraem os jovens para fora da escola. Conforme se nota as taxas de evasão nas regiões mais ricas (São Paulo 20\% e Porto Alegre com 19\% por exemplo.) O crescimento econômico tira os jovens da escola nas regiões mais ricas do país do que nas mais pobres, que não oferecem oportunidade de trabalhos para os filhos e os seus pais.

Nos estudos realizados por Ceratti, (2008), foi constatado que os estudantes alegam que o ensino é difícil porque estão muito cansados devido ao trabalho diário, que aprendem ou 
não as lições, pois além do cansaço não gostam de ler. Ou seja, na percepção da autora, por trás do que os estudantes alegam, existem razões que implica na evasão escolar, medo do fracasso ou de esforçar e falta de autoestima de enfrentar as dificuldades. Dessa forma há uma crença do que o fracasso escolar, tenha as suas causas no próprio estudante, implicando uma neutralidade da escola.

Outros autores, como Medina (2012, P. 6), afirma que "a evasão é produto do enfraquecimento das intenções iniciais e da persistência dos alunos”. O apoio familiar, as expectativas de sucesso, as percepções sobre as dificuldades de estudos, as metas e valores dos alunos também influenciam no sucesso escolar. (Medina 2012).

Essas informações, possibilita na compreensão de que são inúmeros os fatos que impulsionam os jovens para fora da escola. Portanto, mais do que nunca, a sociedade escolar assim, como a familiar, tem papeis importantes na condução dos jovens no acesso e permanência na escola.

Exposição do quadro demonstrativo de resultados anuais no arquivo da escola

- Quadro I: Demonstrativo de Estatísticas do ano letivo - 2017.

\begin{tabular}{|c|c|c|c|c|c|c|}
\hline Turmas & $\begin{array}{l}\text { N.o/ } \\
\text { alunos }\end{array}$ & Aprovados & Reprovados. & Abandonos & Transf. & Retidos \\
\hline $\begin{array}{l}\text { 6. }=\text { ano A } \\
\text { Mat. }\end{array}$ & 34 & 24 & 2 & 4 & 3 & I \\
\hline $\begin{array}{l}\text { 6. }=\text { ano } \mathrm{E} \\
\text { vesp. }\end{array}$ & 30 & 25 & 2 & 2 & I & o \\
\hline Total & 64 & 49 & 4 & 6 & 4 & I \\
\hline$\%$ & $100 \%$ & 76,56 & $6,25 \%$ & $9,38 \%$ & $6,25 \%$ & $1,56 \%$ \\
\hline
\end{tabular}

FONTE: Ata de encerramento do ano letivo-2017, 2.. segmento no ensino fundamental.

- Quadro II: Demonstrativo de Estatísticas do ano letivo - 2018

\begin{tabular}{|l|l|l|l|l|l|l|}
\hline Turmas & $\begin{array}{l}\text { N.o/ } \\
\text { alunos }\end{array}$ & Aprovados & Reprovados & Abandonos & Transf. & Retidos \\
\hline $\begin{array}{l}6.9 \text { ano A } \\
\text { Mat }\end{array}$ & 33 & 27 & I & 2 & 2 & I \\
\hline $\begin{array}{l}6 \text { o ano E } \\
\text { Vesp. }\end{array}$ & 32 & 27 & o & 2 & I & 2 \\
\hline Total & 65 & 54 & I & 4 & 3 & 3 \\
\hline$\%$ & $100 \%$ & $83,08 \%$ & I, $54 \%$ & $6,15 \%$ & $4,62 \%$ & $4,62 \%$ \\
\hline
\end{tabular}


FONTE: Ata de encerramento do ano letivo-2018, 2.. segmento no ensino fundamental.

(Ata de encerramento do segundo segmento no ensino fundamental).

$\checkmark$ Alunos entrevistados do 6. ano:

Foram entrevistados 2 (dois) alunos do sexo masculino da turma do 6o ano A do turno matutino. As mães destes adolescentes participaram da pesquisa.

$\checkmark$ Alunas entrevistadas do 6으 $\mathrm{E}$

Nesta turma 2 (dois) alunas do sexo feminino e as suas respectivas mães foram entrevistados.

\section{ANÁLISE E DISCUSSÃO DOS RESULTADOS.}

Diante do exposto na pesquisa de campo, por questionários, a onde se ouviu quatro alunos $\mathrm{e}$ as suas respectivas mães, ficou evidente os principais fatores responsáveis e determinantes na evasão escolar do município de Itupiranga-PA e, principalmente na unidade escolar pesquisada. Escola Municipal de Ensino Fundamental: Jarbas Gonçalves Passarinho que apresenta os dados por alunos nos mapas de resultado final da sua secretaria nos arquivos, por alunos nos referidos anos letivos. Nessa pesquisa observou e catalogou resultados sobre a evasão escolar nos anos - (2017) 6.ำ ano A matutino e, 6.ำ ano E, vespertino; (2018), 6. ano A matutino e, 6. ano $\mathrm{E}$, vespertino.

Contudo, as informações obtidas nos levam a crer e compreender que os fatores determinantes da evasão escolar são quase que exclusivamente, de natureza social, estrutura ou profissional. Ainda foi associada à resistência dos estudantes em frequentar a escola, além dos fatores mencionados, os fatores externos próximos à escola, como: bares, praças, clubes sorveteiras, etc.

O diretor da unidade escolar em investigação, salienta também que a prostituição infanto-juvenil, o consumo de bebidas alcoólicas, o desrespeito aos pais, uso de drogas ilícitas etc, contribui significativamente para engrossar as estatísticas das escolas municipais da região amazônica no quesito, evasão escolar. Por tudo isso, as escolas têm dificuldade de ofertar, garantir e manter os alunos na escola.

Embora a educação seja a ponte que se põe entre aluno e o saber, tendo como objetivo o desenvolver, o conhecimento sobre os seres sociais e as suas relações com a natureza, irá enfrentar para diminuir assim, as desigualdades sociais e melhorar a qualidade de vida das comunidades. Conforme Corrobora Paro (1996, pr4) "é próprio da atividade educativa o fato 
de ela poder realizar-se a não ser com a participação do aluno e, esta participação é concretizada enquanto o aluno entra no processo e assume o seu papel de objeto e sujeito da educação".

Segundo a visão de Arroyo (1997, p.23), "na maioria das vezes, o ambiente escolar e os responsáveis pelos educandos provocam a evasão dos mesmos, além de ter a responsabilidade de atribuir à desestruturação familiar e o equilíbrio do aluno; o professor e o aluno não têm responsabilidade para aprender, tornando-se um jogo de empurra". Atualmente, a escola precisa estar preparada, e para isso é preciso, que os professores sejam dinâmicos, responsáveis, criativos e que seja capaz de inovar e transformar o seu lugar.

Essas desigualdades sociais também presentes na sociedade brasileira, segundo ARROYO (1991:2I), são resultantes das "diferenças de classes", e são elas que "marcam" o fracasso escolar nas camadas populares, por que:

É essa escola das classes trabalhadoras que vem a fracassar em todos os lugares. Não são as diferenças de clima ou de região que marcam as grandes diferenças entre a escola possível ou impossível, mas as diferenças de classe. As políticas oficiais tentam ocultar esse caráter de classe no fracasso escolar, apresentando os problemas e as soluções com políticas regionais e locais.

Nos estudos de BRANDÃO, et al. (1983,) são apresentados o resultado de uma pesquisa desenvolvida pelo Programa de Estudos Conjunto de integração econômica da América Latina (ECIEL), o qual baseou-se em uma amostra de cinco países latino-americanos, e conclui que:

O fator mais importante para compreender os determinantes do rendimento escolar é a família do aluno, sendo que, quanto mais elevado o nível de escolaridade da mãe, mais tempo a criança permanece na escola e maior é o seu rendimento.

Segundo estudos de Adorno, [...] educação não é modelagem de pessoas, porque não temos o direito de modelar o educando com interferência o seu mundo exterior, também não é a mera transmissão de conhecimento, mas a produção de uma consciência verdadeira, isto seria inclusive da maior importância política, formando pessoas emancipadas, conscientes e racionais (ADORNO, 2003, P.14I).

Em ampla revisão da literatura nacional e internacional sobre evasão escolar e repetência no ensino de Io grau, BRANDÃO, BAETA, \& ROCHA, (1983), citando os estudos de GATTI (198I), ARNS (1978), e FERRARI (1975), explicam que, "os alunos de nível socioeconômico mais baixo têm um menor índice de rendimento e, de acordo com alguns autores, são mais propensos à evasão". 
A mudança de estratégias e relacionamento com os outros seres e ambiente, contribui com novas descobertas. Segundo Wallon, o homem é um ser essencialmente social impossível, portanto, de ter pensado fora do contexto da sociedade em que nasce e vive. Em outras palavras, o homem não social, o homem considerado molécula isolado do resto de seus semelhantes, o homem visto como independente das influências dos diversos grupos que frequenta, o homem visto como imune aos ligados da história e da tradição, este homem, simplesmente não existe (WALLON, 1992).

A sociedade precisa se reinventar para os novos tempos, para inteirar-se, do saber. Pois escola é o local de inteira inclusão e de novos saberes, por isso deve transformar o educando num ser social pensante existente. A pesquisa, torna o saber em um único caminho para transformação humana social dos indivíduos, conduzindo-os para uma visão crítica, conscientizando e preparando-os para viverem em sociedade e assumindo a sua cidadania (MARX, 199I).

Em oposição aos defensores dos fatores externos como determinantes do fracasso escolar das crianças, autores como BOURDIUE, CUNHA, FUKUI e outros, apontam a escola como responsável pelo sucesso ou o fracasso dos alunos das escolas públicas, tomando como base as explicações que viriam desde o seu caráter reprodutor até o papel e a prática pedagógica do professor.

Fatores intrínsecos e extrínsecos à escola como as drogas, sucessivas reprovações, prostituição, falta de incentivos da família e da escola, necessidade de trabalho, excesso de conteúdos escolar, alcoolismo, vandalismo, falta de formações de valores e prepara para o mundo do trabalha influenciam diretamente nas atitudes dos alunos que se afastam da escola. Esses obstáculos, considerados, na maioria das vezes, intransponíveis para milhares de jovens, engrossam os desempregos ou contingentes de trabalhadores barata. Em pesquisa feita pela Fundação Getúlio Vargas/FGV, Neri (2009) afirma que o mercado de trabalho é um ator importante na tomada de decisão desses jovens que teimam em terminar seus estudos para sobreviver, ou desiste e torna uma trabalhadores desqualificada para garantir a sua sobrevivência. As escolas não ficam isoladas deste contexto. Segundo Dourado (2005).

Segundo Viadero, (200I), Finn (1989), a evasão escolar pode ser ainda representada por aqueles indivíduos que nunca ingressaram em um determinado nível de ensino. Outro aspecto considerado importante nessas situações, concernem ao nível escolar em que estas ocorrem, pois, o abandono da escola fundamental, ou até de nível médio Montrmarte Mahseredjian, Haule, zoor é significativamente diferente daquele que ocorre na educação de adultos ou na educação superior. 
Além da questão trabalho, outras, inerentes ao fracasso escolar, são destacadas com muita evidência pelas estatísticas educacionais, segundo Dourados, (2005), resultado de processos sociais mais amplos e que tem sido reforçado no cotidiano escolar por meio de práticas e ações pedagógicas e pelas formas de organização e gestão de educação básica. DOURADOS (2005 p. II)

\section{CONSIDERAÇÕES FINAIS}

Em relevância a todas as informações analisadas, sejam elas em âmbitos local, regional, nacional e global, entende ser que a situação "evasão escolar”, é complexa, ampla e inclui uma infinidade de fatores e, em tempos diversos, portanto, de difícil compreensão, pois esse processo perpassa por um conjunto de acontecimentos heterógenos em escalas diferentes.

Portanto, o termo "evasão e abandono escolar", é visto como um fato angustiante para todos os envolvidos do processo educacional, é percebido como uma das fraquezas do sistema da educação brasileira e, que está longe de ser resolvida, afeta os diferentes níveis de ensino e modalidades nas instituições e privadas. Estas instituições têm sido alvos de políticas educacionais confusas que não se sustentam por muito tempo, ou seja, tempo condição de excelência, isso é sentido na falta de identidade de ensino, que necessita ser posto em discussão para se busque meios reais para enfrentamentos.

Diante do que é exposto, faz se necessário uma mudança que não seja uma simples adaptação passiva da situação, mas que busque condições satisfatórias para encontrar um lugar próprio e aberto para a construção do novo, permitindo assim a expansão de potencialidade e habilidades humanas e a emancipação de ideias coletivas, com um olhar em todas as direções e dimensões históricas, cognitivas, sociais, afetiva e cultural.

É expressamente percebido que os fatores sociais, culturais, econômicos e políticos, bem como também os escolares, nos quais educadores colabora a cada dia para o problema se agravar, mediante a um método didático pedagógico superado ou de uma prática cristalizada como por inexperiência acabam por desenvolver um conteúdo descontextualizado e sem sentido para o aluno.

Como se ver, é preciso criar formas para enfrentar esse paradigma e possibilitar novas perspectivas ao sistema escolar e ao aluno, capazes de amenizar as causas que elevam à superação de dificuldades para a diminuição da evasão e o abandono escolar, por compreender que estas não foram analisadas de formas adequadas e necessárias como uma proporção de alternativa para diminuição do índice de evasão em sentido amplo.

Entende também que para a transformação em busca do novo, a mediação da família é muito importante, pois permite ao aluno permanecer mais tempo nas instituições de ensino 
e concluir seu curso, visto que para muitos, a escola é o único lugar de informações. Além disso, a cultura, o trabalho e tempo, que visa na construção de um currículo e deve a escola ser fator fundamental para o desenvolvimento como ser social e intelectual.

Logo se percebe que o fracasso da escola tido como evasão e abandono escolar, originam-se em fatores internos e externos, portanto, devem ser tratados com a mesma dimensão e solucionados para o equilíbrio do sistema e a aprendizagem do estudante.

\section{REFERÊNCIAS BIBLIOGRÁFICAS}

ARROYO, Miguel. Balanço da EJA: O que mudou nos modos de vida dos Jovens - Adultos populares, 200I.

MARX, Karl, o capital: crítica sobre a economia e a educação. Livro 2. Civilização. 2002.

ADORNO. PUCCI, L. LASTORIA, L. N. (Orgs). io lições sobre a visão de Ardono. Petrópolis; Vozes, 2015.

WALLON, H. Do ato ao pensamento: ensaio de psicologia comparada. Petrópolis: Vozes 2008.

SILVA, Caio Ruano da; PIMENTEL, Beatriz Rios, FINARDI, Kyria Rebeca. Refletindo sobre evasão em curso técnico. UNOPAR. Cient., Cienc. Human. Educ., Lodrina, v. 15, n, 3, p.239-247,out. 2014 .

QUEIROZ, Lucileide Domingos. Um estudo sobre evasão escolar: para se pensar na inclusão escolar. Associação Nacional de Pós-Graduação e Pesquisa em Educação; (Anped), v.3,20oI. Disponível em:< $w$ ww.anped.org.br/reuniões/25lucileidedomingosqueirozt13.rtf.>.Acesso em: 20 de abr. 2016.

LÜSCHER, Ana Zuleima; DORE, Rosemary. Política educacional do Brasil: educação técnica e evasão escolar. Revista Brasileira de Pós-graduação. Brasília. sulp. ı, v. 8, p. I47-ı76,20II.

NERI, Marcelo Côrtes. Movimento da Evasão Escolar. Rio de Janeiro: FGV, 2009.

MEDINA, Maria Angélica Lozano. Causa de evasão em programas de qualificação profissionais: Análises dos casos de Osasco e Bogotá. Repositório digital FGV. Coleções EAESP - MPGPP. Trabalhos individuais, 2012.

CERATII, Marcia Rodrigues Neves. Evasão escolar, causas e consequências. Curitiba/PR, 2008. Disponível em < http:// www.see.go.gov.br/imprensa/documentos,/arquivos/15\%20\%Manual\%...Combate\%20\%... evasão escolar\% Acesso em: I4 de jul, 2016.

ARQUIVOS da escola Jarbas Gonsalves Passarinho, Av i4 de Julho s/n Pç central Itupiranga - PA (pesquisa em 2017/2018). 
BRANDÃO, Zaia,et alii. $O$ estado da arte da pesquisa sobre a evasão e repetência no ensino de Io grau no Brasil. In Revista Brasileira de Estudos Pedagógicos, v. 64, no 147, maio/agosto 1983, p. 38-69.

BOURDIEU, P,; PASSERON,J. C. A reprodução: elementos para uma teoria de sistema. Rio de Janeiro: Francisco Alves, 1975.

CUNHA, L.A. Ensino médio e ensino profissional: da fusão a exclusão. In: REUNIÃO ANUAL DA ANPED, 20; Caxambu, 1997; (mimeo).

DOURADO, Luiz Fernandes. Elaboração de políticas e estratégias para a prevenção do fracasso escolar - Documento Regional BRASIL: Fracasso escolar no Brasil: política, programas de prevenção e estratégias ao fracasso escolar.2005.

FERREIRA,F.A.Fracasso e evasão escolar. 2013. Disponível em:http://educador.brasilescola.com/orientacao.escolar/fracasso-escolar.htm. Acesso em: 20 maio 2016.

FINN, J. D. Withdrawing fron school. Review of educational research, v.59, n. p. II7-I42, I989.

GATTI, Bernardete. A.; VIANNA, Heraldo Marelim; DAVIS, Cláudio. Problemas e impasses da avaliação de projetos e sistemas educacionais: dois estudos de caso. In, Avaliação Educacional, São Paulo, p. 7-26, jul.-dez. 1991. 